\title{
"Em terra de gente nua": o humor como estratégia política em um jornal dirigido por Oswald de Andrade
}

Valdeci da Silva Cunha ${ }^{75}$

Ninguém pode articular uma sillaba que não esteja cheia de ternuras e de temores

(Jorge Luís Borges)

Resumo: A proposta tem como objetivo analisar o jornal $O$ Homem do Povo, de autoria de Oswald de Andrade, publicado no ano de 1931, no que diz respeito a qual seria o lugar, a função e os usos do recurso ao riso e ao humor na escrita oswaldiana. Para isso, consideramos Oswald como homem do seu tempo, inserido em debates e polêmicas de sua época, sendo essa publicação objeto e meio de divulgação de seus pensamentos e críticas, assim como propostas no campo das possibilidades de interferências/modificação da realidade. Contudo, sabe-se que esse não foi o único empreendimento jornalístico em que esteve envolvido. Nesse sentido, intenta-se compreender o conteúdo político desse pasquim, na trilha da história político-intelectual, assim como apreender quais teriam sido as relações que o mesmo estabeleceu no campo intelectual brasileiro. Aporia esta que, talvez, nos dê a possibilidade de dimensionar um projeto político abortado imaturamente.

Palavras-chaves Oswald de Andrade, Pensamento Político, Jornalismo

\section{Introdução}

No ano de 1931, Oswald de Andrade deu início à publicação de um jornal político - marcado por uma efêmera existência ${ }^{76}$ - intitulado 0 Homem do Povo. Em formato tablóide, de $48 \mathrm{~cm}$ por $34 \mathrm{~cm}$, era composto de seis páginas, organizado em colunas e apresentava artigos sobre variados assuntos. Formalmente, era composto em seções de curtas dimensões e poucas palavras, não chegando a ocupar toda uma página com um único assunto.

Os números analisados são escassos de informações sobre as possíveis estratégias de publicação colocadas em movimento pela redação do impresso. Com efeito, esse complicador nos coloca uma dupla lacuna: a impossibilidade de conseguirmos trabalhar as dimensões que diriam respeito à sua tiragem e aos espaços de sua circulação. Nesse sentido, apenas algumas informações sobre possiveis assinaturas estão presentes desde o primeiro número (o jornal trazia o valor de "preço de venda: 200 réis; assinaturas: $40 \$ 000^{\prime \prime}$ ). A ausência desses dados, ao menos até o momento do andamento da pesquisa, nos impossibilita de trabalhá-lo no âmbito da circulação de impressos. Contudo, partimos de

\section{Mestrando em História pela UFMG}

76 O jornal teve seu primeiro número publicado no dia 27/03/1931. Por motivo de seu empastelamento, foram publicados apenas 8 números, sendo o último no dia 13/04/1931. 
seu conteúdo textual para efeito de análise, pois entendemos que seriam pela linguagem, e nela, que as propostas políticas oswaldianas estariam manifestas (BAKHTIN, 1981, p. 81).

Ao pensarmos na linguagem das fontes para a pesquisa histórica, especialmente no trabalho em questão, consideramos que o sentido e significação da linguagem são fornecidos pelo contexto e pelas condições de enunciação. As palavras que falamos, ouvimos, escrevemos e lemos seriam, nesta abordagem, idéias portadoras de valores socialmente atribuídos. A linguagem e as classificações que ela expressa atuariam, assim, como princípios de (di)visão do mundo social. Um recurso que, ao permitir nomear as coisas do mundo, modifica-o. As descrições muitas vezes são prescrições: há algo de denúncia naquilo que se anuncia. As propriedades da língua em transformar o mundo social só são compreensíveis se admitirmos o social como relacional ao invés de substancial.

Estamos tratando o mundo social, de acordo com Pierre Bourdieu, como relacional. A "realidade" é o lugar de luta, permanente para definí-la. As representações "que os agentes sociais possuem das divisões da realidade contribuem para a realidade das divisões". Acreditamos que os problemas denunciados pelo ethos político do jornal não devem ser tratadas somente na sua dimensão objetiva (independente da consciência e da vontade dos agentes e que são capazes de orientar e coagir suas práticas e representações), mas devem ser consideradas na sua dimensão subjetiva (esquemas de percepção, pensamento e ação) que a tornam aceitável ou condenável (BOURDIEU, 1989; 1990; 1996).

\section{Mais luz, mais sombra}

Política e ideologicamente, sentido esse que mais nos interessa nesse artigo, qualificamos o jornal em questão como um pasquim ${ }^{77}$, tanto por seu conteúdo quanto por sua forma, seu caráter difamatório e público, por usar uma linguagem bem específica. Nesse sentido, traz uma escrita direta, utilizando uma linguagem objetiva, com um sentido manifesto de persuasão para ação, como proposto no trecho a seguir:

[...] falo sério e penso em ti homem do povo! No dia em que saíres dos teus tugúrios sujos, das tuas usinas encarvoadas, dos teus quartéis [...] alegremente subiremos para conversar, aos ricos salões e às casas fúteis da pequena burguesia, de onde eles saíram agora para agredir em batalhão uma mulher e um homem do povo ${ }^{78}$.

Prognosticamente, ao fazer referência à Faculdade de Direito do Largo São Francisco, em 
São Paulo - que havia sido alvo de ataques recentes pelo jornal -, Oswald utiliza-se de uma equação em que o argumento de desqualificação das atitudes dos estudantes de Direito cria, por efeito, a sua aproximação daqueles que seriam os supostos alvos principais - os homens do povo. Nesse sentido, o desdobramento estaria na "autorização de sua fala" (BOURDIEU, 1996, p. 89), ou seja, o ato de enunciar a condição de vida dos trabalhadores traz implícita a denúncia de uma situação de injustiça e distinção entre duas realidades sociais.

O uso do recurso de pseudonímia ${ }^{79}$ nas assinaturas das seções também nos leva a um universo de criação argumentativa mais solta e despojada, em uma ânsia de expressão que se traduziria na tentativa de se colocar livre das amarras sociais ou preceitos/limites próprios do espaço do político. Fica evidente pouca ou quase nenhuma "reticência" no que diz respeito às necessidades de ação e/ ou de um reforço da recriação desse espaço.

Em outra passagem, ao noticiar a chegada dos príncipes de Gales a São Paulo, o jornal enfatiza a necessidade de posicionamento em relação à "explosão imperialista" que também atingia outros países, como a Índia: "(...) chegam hoje a São Paulo dois homens que habitualmente figuram nos livros de fadas. São príncipes. Isso, que na imaginação das crianças tem uma importância monumental, significa em nossos dias, uma realidade trágica" (OHP, 1931, № 2).

Somado a essas características, podemos relativizar o alcance e intenção do próprio título do jornal, ao conjugarmos ambos com o seu conteúdo mais explícito. Ou seja, um jornal que teria como função e projeto alertar o "homem do povo" para as mazelas e os problemas que afligiam sua vida. Nesse sentido, chamando-o para a reflexão sobre a sua condição ou para a percepção do mundo que o cercava, uma vez que esse aparece como tradução do distanciamento da vida social (ou mesmo do jogo político):

O homem do povo, que trabalha, que sai cedo de casa pra fábrica, a oficina, o escritório, o armazém, só dispõe para tanto dos poucos minutos da viagem de bonde, e o que lhe importa são as notícias rápidas, concisas, concretas. É o que esse novo jornal, que além de novo é pequeno e não pretende chegar a venerando, vai fazer, nesta página, sumariando em quatro linhas os acontecimentos mundiais da véspera (OHP, 1931, n1).

Propunha que a salvação para o (e do) homem brasileiro viria do questionamento da classe dominante: “mas quem é essa elite, em cujas mãos se monopolizam os 'meios de produção'. Imbecis de todas as espécies, moços que não têm um dedo de conhecimento de vida, coronéis inviris e de mulheres feias, vazias e recalcadas" (OHP, 1931, $n$ ㅇ 2).

No periódico, de uma maneira geral, dessacralizava-se o tom eloqüente da prática jornalística. Ao recorrer à sátira, ao reabilitar a linguagem cinematográfica utilizada anteriormente pelo autor e se valer de algumas charges, 0 Homem do Povo inseria o discurso político fortemente marcado por

79

Apareceram, com certa freqüência, assinaturas como Zumbi, Álcool-motor, O homem do povo, Cobra, Plebeu, dentre outras, característica essa presente em outros momentos da produção oswaldiana. Ver, por exemplo, "Boêmia e vanguarda". In: CHALMERS, Vera M. 3 linhas e 4 verdades: o jornalismo de Oswald de Andrade. São Paulo: Duas cidades, 1976, pp. 45-50. 
uma "deglutição radical" de cunho antropofágico ${ }^{80}$. Chega a se referir a Luiz Carlos Prestes como "o grande chefe da revolução social", quando da denúncia e posicionamento desse em relação à escolha de um político local (Capitão Távora), por Getúlio Vargas, para a presidência do norte - não explicitada pelo texto. Para Oswald, "Luiz Carlos Prestes acaba[ra] de desmascarar o super-generalíssimo que continuará, no entanto, nos postos de confiança que lhe deu o governo atual” (OHP, 1931, no 2).

Criticando a dominação imperialista, ao mesmo tempo em que tentava apontar saídas para a realidade brasileira, Oswald de Andrade mantinha seu discurso carnavalizador em algumas passagens, como, por exemplo: "(...) dum país que possui a maior reserva de ferro e o mais alto potencial hidráulico, fizeram um país de sobremesa. Café, açúcar, fumo, bananas. Que nos sobrem ao menos as bananas".

Em outra passagem:

[...] num país que vai a pique, também aparecem músicos. São os embaixadores que levam para o Exterior a harmonia falsa de um fox-trot sem sentido que não faz mais nenhum credor dançar. Detentores de uma mentalidade postiça, habituada ao teórico, ao convencional e ao falso, eles são destacados para iludir com baixelas e bons modos, a perturbação imensa que se apodera de uma nau que faz água e a cujo trágico SOS respondem outros chamados de outros naufrágios, num mar que não brinca, que não adia a catástrofe, que não perdoa e não recua diante de milagre nenhum (OHP, 1931, no 3).

Se todo "horizonte de expectativa" remete a um "espaço da experiência" vivida e compartilhada entre uma dada sociedade no tempo e no espaço - em uma relação dinâmica entre o passado e futuro (KOSELLECK Apud REIS, 2006, p. 24) - podemos supor a possibilidade de uma "filosofia da história" na construção argumentativa de Oswald de Andrade. Ao que parece, uma revolução social estaria em curso - se não, ao menos sendo conformada em relação à sua forma de lidar ou se relacionar com a realidade em que estaria inserido. Percebemos uma concepção teleológica da história da sociedade brasileira - ao menos em relação a esse momento específico que poderia ser considerado como um "marco zero" do envolvimento político de Oswald de Andrade. Ao mesmo tempo em que se colocava como um mediador político e cultural, ou reivindicava esse lugar junto às "massas", em torno dos usos da idéia de povo, chegou a afirmar, em determinados momentos, um estágio já desenvolvido da consciência do trabalhador no que diz respeito à sua própria existência. Ao se referir às condições de moradia de alguns trabalhadores de São Paulo, denuncia que "o pobre, o operário, o habitante das zonas ribeirinhas vai sofrendo. O pão é escasso, o trabalho nas fábricas dos ricos é duro, a roupa é pouca”.

Na seqüência, conclui:

Que quer o povo? Quereria morar em palácios? Sujos, sem maneiras, que melhor poderiam ter? Não. Decididamente não são iguais as gentes desde nosso velho mundo [...]. Mas felizmente já os pobres, os que trabalham estão certos de que só podem contar consigo, que os burgueses, os ricaços, os confortáveis são sempre os seus inimigos. E que para melhorarem as suas condições de

80 Aqui, estamos pensando especificamente nas obras Memórias sentimentais de João Miramar e em Serafim Ponte Grande nas quais podemos perceber uma estrutura montada a partir seqüências descontinuas, formando quase um mural. Para mais informações entre as relações entre técnica e escrita, ver: SUSSEKIND, Flora. $O$ cinematógrafo das letras: literatura, técnica e modernização no brasil. São Paulo: Companhia das Letras, 1987. 
existência tem de aniquilar os seus inimigos de todos os tempos (OHP, 1931, nำ2).

O início dos anos 30 do século XX marca a aproximação de Oswald com o Partido Comunista Brasileiro. Entretanto, sua trajetória pelō mesmo foi marcada por alguns particularismos. Para Maria Eugenia Boaventura, ao se referir à posição de intelectual engajado, as reflexões de Oswald, nesse momento,

[...] foram marcadas pelo caráter didático, à semelhança de roteiros para conferência ou aulas destinadas a operários; também funcionaram como programa, orientação à discussão interna entre os companheiros de partido, ou ainda resultaram em planos de edições que visassem ao aprimoramento cultural do trabalhador (BOAVENTURA, 1995, p. 178).

Ao que parece, Oswald de Andrade deu um significado particular para a sua relação com o pensamento de esquerda (ou marxista):

$\mathrm{Na}$ fase de relacionamento com o Partido Comunista, Oswald não perdeu o entusiasmo pelas teorias anarquistas que o animaram, desde o seu tempo de estudante de Direito. A sua produção da década refletiu essa atmosfera, embora apresentasse idéias opostas aos princípios do partido (Idem, Ibidem, p. 180).

Algumas passagens do jornal nos dão algumas pistas sobre essa atitude de "deglutição antropofágica" às suas posições em relação tanto à sua exótica filiação partidária - "para tal fim discutiremos todos os problemas sociais, econômicos e financeiros, em forma popular, para serem compreendidos pela massa menos culta da população afim que essa aprenda a opinar" -, quanto à argumentação em relação à luta de classes - "não queremos depender dos favores dos ricos nem dos governos [...] não consideramos somente classes pobres os trabalhadores rurais e urbanos, mas também os indivíduos que pertencem á miséria da gravata" (OHP, 1931, № 1).

Se no início dos anos de 1920 podemos perceber a postura de Oswald ligada a uma forma "elitizada" de lidar com a realidade social e/ou política brasileira, o início dos anos de 1930 seria marcado por uma inversão do sentido da "seta", isto é, suas posturas enquanto intelectual estariam "a contra pêlo" de suas posições ou lugares sociais ocupados naquele momento. Para Sérgio Miceli, aquele primeiro momento seria marcado por relações estabelecidas entre os intelectuais e o poder (Estado):

[...] os "feitos" dos escritores modernistas em matéria de decoração, de vestuário, de ética sexual etc. inscrevem-se com maior acerto na história da importância dos padrões de gosto da classe dirigente ligada à expansão do café do que na história da produção intelectual (MICELI, 1979, p. 97).

Nesse sentido, Oswald significaria mais do que um personagem ligado única e exclusivamente a novas propostas estéticas. Ele estaria ligado aos pertencentes das famílias abastadas, produzindo para um número bastante reduzido de "iniciados", sempre na dependência de meçenas, "que detinham as chaves para decifrar tais obras" (Idem, Ibidem, p. 97). As experiências estéticas, 
assim, estariam ligadas às suas várias viagens feitas tanto para o exterior quanto para o interior do país.

No ano de 1933, Oswald de Andrade publica o prefácio definitivo de sua mais importante obra, Serafim Ponte Grande. Antes da edição final, o livro recebera um outro prefácio, de 1926. Nele é perceptível a disputa pela tentativa de "canonização" do Movimento Modernista como escola literária - assim como a tentativa de ratificação da Antropofagia - na medida em que apresentava o romance como um processo acabado de uma literatura "verdadeiramente" nacional. No prefácio de 33, Oswald assumia uma postura definitiva, negando seu passado burguês ao afirmar estar "possuído de uma única vontade. Ser, pelo menos, casaca de ferro na Revolução Proletária" (ANDRADE, 1988, p. 10).

Uma das preocupações recorrentes de Oswald de Andrade, no início dos anos de 1930, também estava ligada ao crescimento do número de partidários de um modelo de política de orientação conservadora - principalmente o crescimento de manifestações favoráveis ao fascismo. Entre os intelectuais atacados pelas colunas de O Homem do Povo, encontramos Plínio Salgado ocupando posição central ${ }^{81}$. A primeira polêmica-reação contra as posições adotadas por Salgado manifestouse, já no primeiro número do impresso, uma vez que, para Oswald, "Plínio (Saldoce) da[va] [à]noção de classes um sentido anedótico - profissional", isto é, negava a existência de antagonismos entre os dois pólos da disputa. Em outra passagem, utiliza-se da definição da figura do "Macróbio" nas relações políticas, que se apresentaria como o "cavalheiro que fala de cima para baixo nas colunas do Diário Popular". Seria ainda o detentor da "ciência palavrosa que conhece todos os assuntos que trata"; "diz o que é e o que não é... "; "[do] bacharelismo sábio" (OHP, 1931, no 1).

Sobre o comunismo, o jornal tece críticas em relação ao suposto pouco domínio dos que se prestavam a tratar do assunto:

(...) senhores de meias verdades, julgam sempre haver alcançado a verdade absoluta [...] a verdade inteira só conhece o Macróbio, porque a colhe nas revistas, fresquinhas, fácil, a tesouradas, e com uma goma arábica e jeito justapõe nas suas crônicas [...]. Pois bem, sr. Macróbio, eu vou explicar-Ihe em poucas palavras o que é o comunismo, que você, como o Sr. Plínio Salgado e outros dicionários de sua espécie, tem passado a vida a estudar jogos de palavras, flores de retórica sobre todos os assuntos, mas de fato não conhecem bem assunto algum (OHP, 1931, no 1).

Ao evidenciar algumas disputas que se traduziram nas diferenças propositivas entre os manifestos Antropofágico e Verde-amarelo ${ }^{82}$, O Homem do Povo ataca Plínio Salgado com relação ao que, em seu manifesto, vinha inscrito sob a sigla da cópia. Com efeito, sua flecha se direciona ao livro de Salgado intitulado Estrangeiro que, "apesar da sua idiossincrasia por toda espécie de imitação dos figurinos exóticos, não passa de uma tradução brasileira das idéias de Benito Mussolini". Essa postura 81 Com menor ênfase, apareceram outros que, segundo o jornal, teriam contribuído de alguma forma, mesmo que no passado, para a produção-reprodução de um país marcado por desigualdades sociais. Entre estes, Rui Barbosa, qualificado pelo impresso como o "maior bandido morto do país", em um concurso em que o jornal pedia para os leitores suas opiniões sobre qual seria o maior bandido vivo do Brasil.

82 Para mais informações, inclusive as transcrições de ambos os manifestos, ver: TELES, Gilberto Mendonça. Vanguardas européias e modernismo brasileiro. Petrópolis: Vozes, 1983 
- "não nos parece, pelo que vimos, senão um meio hábil de despistar o leitor desprevenido" - foi desqualificada por Oswald no que diz respeito ao papel de um autor inserido no âmbito das artes, literatura, legislação e até nos costumes. Percebe-se também a utilização de algumas expressões negativas na tentativa de denegrir a imagem de Plínio ao se referir a ele como "romancista bicolor". Para criar um efeito de validade de seu discurso, explicita vários trechos, em uma leitura comparada, de partes do Manifesto Verde-amarelo e de "igualmente frases ocas e sonoras do chefe atual do governo italiano" (OHP, 1931, no 2).

\section{Conclusão}

Assim, na tentativa de um pequeno estudo sobre a produção jornalística de um intelectual, espera-se ter sido possível uma apreensão inicial de suas inquietações pelos meandros da história do pensamento político brasileiro.

Ao invés de "julgarmos" o legado oswaldiano ou nos posicionarmos contra ou a favor de suas ações - como as suas prisões por envolvimento político ou as acusações de plagiador que recebeu em alguns momentos de sua vida -, nos preocupamos em tentar compreendê-lo, deixá-lo "falar". Com efeito, acompanhar a sua argumentação por meio de seu efêmero jornal e dos debates que alimentou ou nos quais se posicionou.

Se, para um pensador como Benjamin, seria possível "nos aproximarmos de histórias que teriam sido, se não fossem preteridas pela historiografia dominante" ${ }^{\prime 83}$, esse diálogo pode se tornar mais consistente e, ao ser explorado, apresentar possibilidades para a melhor compreensão de algumas lacunas do passado brasileiro. 